\title{
Availability of nutritional support services in HIV care and treatment sites in sub-Saharan African countries
}

\author{
Aranka Anema ${ }^{1,2, *}$, Wendy Zhang ${ }^{1}$, Yingfeng $\mathrm{Wu}^{3}$, Batya Elul ${ }^{3,4}$, Sheri D Weiser ${ }^{5}$, \\ Robert S Hogg ${ }^{1,6}$, Julio SG Montaner 1,2, Wafaa El Sadr ${ }^{3,4}$ and Denis Nash ${ }^{3,4}$ for the \\ International Center for AIDS Care and Treatment Programs \\ 'British Columbia Centre for Excellence in HIV/AIDS, St. Paul's Hospital, 608-1081 Burrard Street, \\ Vancouver, BC V6Z 1Y6, Canada: ${ }^{2}$ Department of Medicine, Faculty of Medicine, University of British \\ Columbia, Vancouver, BC, Canada: ${ }^{3}$ International Center for AIDS Care and Treatment Programs (ICAP), \\ Columbia University Mailman School of Public Health, New York, NY, USA: ${ }^{4}$ Department of Epidemiology, \\ Columbia University Mailman School of Public Health, New York, NY, USA: ${ }^{5}$ Center for AIDS Prevention \\ Studies, University of California San Francisco, San Francisco, CA, USA: ${ }^{6}$ Faculty of Health Sciences, \\ Simon Fraser University, Burnaby, BC, Canada
}

Submitted 4 October 2010: Accepted 28 April 2011: First published online 2 August 2011

\begin{abstract}
Objective: To examine the availability of nutritional support services in HIV care and treatment sites across sub-Saharan Africa.

Design: In 2008, we conducted a cross-sectional survey of sites providing antiretroviral therapy (ART) in nine sub-Saharan African countries. Outcomes included availability of: (i) nutritional counselling; (ii) micronutrient supplementation; (iii) treatment for severe malnutrition; and (iv) food rations. Associations with health system indicators were explored using bivariate and multivariate methods. Setting: President's Emergency Plan for AIDS Relief-supported HIV treatment and care sites across nine sub-Saharan African countries.

Subjects: A total of 336 HIV care and treatment sites, serving 467175 enrolled patients. Results: Of the sites under study, 303 (90\%) offered some form of nutritional support service. Nutritional counselling, micronutrient supplementation, treatment for severe acute malnutrition and food rations were available at 98\%, 64\%, 36\% and $31 \%$ of sites, respectively. In multivariate analysis, secondary or tertiary care sites were more likely to offer nutritional counselling (adjusted OR (AOR): $2 \cdot 2$, 95\% CI $1 \cdot 1$, 4.5). Rural sites (AOR: 2·3, 95\% CI 1·4, 3·8) had increased odds of micronutrient supplementation availability. Sites providing ART for $>2$ years had higher odds of availability of treatment for severe malnutrition (AOR: 2·4, 95\% CI 1·4, 4·1). Sites providing ART for $>2$ years (AOR: 1·6, 95\% CI 1.3, 1.9) and rural sites (AOR: $2 \cdot 4$, $95 \%$ CI $1 \cdot 4,4 \cdot 4$ ) had greater odds of food ration availability.

Conclusions: Availability of nutritional support services was high in this large sample of HIV care and treatment sites in sub-Saharan Africa. Further efforts are needed to determine the uptake, quality and effectiveness of these services and their impact on patient and programme outcomes.
\end{abstract}

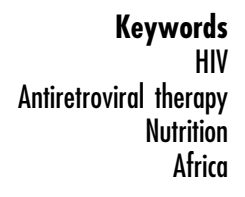

An estimated $22 \cdot 5$ million adults and children were living with HIV/AIDS in sub-Saharan Africa in $2009^{(1)}$. Access to triple combination antiretroviral therapy (ART) has led to significant decreases in morbidity and mortality ${ }^{(2-4)}$. On the basis of the new WHO criterion for treatment initiation (CD4 cell count: $\leq 350$ cells $/ \mathrm{mm}^{3}$ ), ART was accessed by an estimated $37 \%$ of sub-Saharan Africans in need of ART by the end of $2009^{(5)}$. The United Nations Food and Agriculture Organization estimates that 239 million people were chronically undernourished in sub-Saharan Africa in $2010^{(6)}$. A significant proportion of people living with HIV/AIDS in the region are simultaneously affected by nutritional deficiencies ${ }^{(7)}$. The WHO classifies nutritional status by BMI as mild $\left(\mathrm{BMI}=17 \cdot 00-18 \cdot 49 \mathrm{~kg} / \mathrm{m}^{2}\right)$, moderate $\left(B M I=16 \cdot 00-16.90 \mathrm{~kg} / \mathrm{m}^{2}\right)$ or severe $\left(\mathrm{BMI}<16 \cdot 00 \mathrm{~kg} / \mathrm{m}^{2}\right.$, bilateral pitting oedema) ${ }^{(8)}$. Cross-national population-based data suggest that the prevalence of mild and moderate malnutrition among adults living with HIV/AIDS is $15 \cdot 4 \%$ and $10 \cdot 3 \%$, respectively, in sub-Saharan Africa ${ }^{(9,10)}$, and is also elevated among young children living in AIDSaffected households ${ }^{(11)}$.

The disproportionate burden of HIV/AIDS and nutritional deficiencies in sub-Saharan Africa is of particular concern as each condition may perpetuate and aggravate 
the severity of the other ${ }^{(12)}$. HIV/AIDS affects people during the most productive years of their life, resulting in decreased household economic capacity and agricultural output and increased caregiver burden ${ }^{(13)}$. HIV infection may worsen nutritional status or compound pre-existing malnutrition by increasing an individual's metabolic rate and resting energy expenditure ${ }^{(14-16)}$ and by reducing one's ability to effectively absorb and utilize nutrients ${ }^{(16-18)}$. Conversely, nutritional deficiencies have been shown to result in poorer clinical outcomes among HIV-infected individuals, including those on ART, in both high- and lowresource settings ${ }^{(19)}$. Compliance with dietary requirements has been shown to be important for the absorption of certain antiretroviral drugs ${ }^{(20)}$. Demands of food costs have been cited as barriers to ART uptake in Africa ${ }^{(21,22)}$. Among individuals receiving ART, food insecurity and poor nutritional status have been associated with decreased adherence to $\mathrm{ART}^{(23-25)}$, reduced CD4 cell count and incomplete HIV RNA suppression in marginalized urban populations of high-resource countries ${ }^{(24,26-28)}$. Food insecurity among individuals on ART has been additionally associated with poorer survival, even when controlling for ART medication adherence $^{(29)}$. Several Africa-based studies have found that low BMI and severe anaemia are independently associated with increased risk of mortality within the first 3 months of ART among adults and children alike ${ }^{(30-32)}$.

In order to mitigate the adverse effects of food insecurity on HIV outcomes, international organizations such as the WHO, the Joint United Nations Programme on HIV/AIDS, the World Food Program (WFP) and major HIV initiatives such as the US President's Emergency Plan for AIDS Relief (PEPFAR) recommend the integration of nutritional support services, specifically nutrition assessment, education and counselling, into HIV/AIDS treatment and care programmes, with PEPFAR allocating \$US 130 million to support the integration of HIV and nutritional support services in $2010^{(7,15,33-36)}$. Since 2006, PEPFAR implementation guidelines have recommended the provision of nutritional evaluation and food support to all orphans and vulnerable children, to HIV-positive pregnant and lactating women and to all adults receiving ART with clinically defined malnutrition. However, little is known about the extent to which nutritional support services are available in HIV care and treatment programmes across sub-Saharan Africa.

We describe here the reported availability of different types of nutritional support services in a sample of 336 HIV care and treatment sites in nine sub-Saharan African countries, as well as correlates of their availability and changes in reported availability over time.

\section{Methods}

The present study involved 336 HIV care and treatment sites from nine sub-Saharan African countries (Kenya, Tanzania,
Ethiopia, Rwanda, Mozambique, South Africa, Nigeria, Lesotho and Cote d'Ivoire) that were receiving technical support from the International Center for AIDS Care and Treatment Programs (ICAP; www.columbia-icap.org) at Columbia University's Mailman School of Public Health.

\section{Programme and facility characteristics}

Data on programme-level characteristics were gathered through routinely conducted, structured site assessments completed by ICAP field staff. Programme and Facility Characteristics Tracking System (PFaCTS) assessments capture information through interviews with facility staff regarding: the type of facility (primary, secondary or tertiary), availability of other HIV-related services (e.g. prevention of mother to child transmission programme, voluntary counselling and testing (VCT), tuberculosis treatment), ancillary patient support services (e.g. peer education, outreach for patients who miss clinic visits, nutrition or food support), laboratory services (e.g. availability of $\mathrm{CD} 4$ testing) and staffing characteristics (e.g. number or type of providers). Three rounds of site assessments had been conducted at the time of interview (January 2007, July 2007 and July 2008). Reliability of survey responses between rounds was assessed for 305 sites and was found to be $91 \%$ overall and $89 \%$ for the nutrition-related questions. Test-retest agreement was recently assessed at fifty-eight ICAP-supported sites in seven of the nine countries included in the present analysis by comparing survey responses with those assessed through repeat survey administration by a supervisory team. For the thirty-one questions that were assessed, agreement between the two methods was $83 \%$ overall and $75 \%$ for the nutritionrelated questions that were assessed.

The PFaCTS survey prompted facility staff to report on the availability of nutritional evaluation (measurement of height and weight), nutritional counselling, micronutrient supplementation, treatment for severe malnutrition in adults and children, and food rations. Clinical admission into supplementary and therapeutic feeding programmes to treat moderate and severe acute malnutrition, respectively, is determined by national guidelines or WHO cut-off points ${ }^{(33)}$.

\section{Inclusion criteria and survey response rate}

Our sample included a total of 336 (96\%) of the 351 ICAPsupported HIV care and treatment sites that completed at least one PFaCTS survey by July 2008. Fifteen sites were not included in our analysis because of incomplete data or information. Among the 336 sites included in our analysis, 174 sites had completed all three survey rounds (January 2007, July 2007 and July 2008).

\section{Statistical analyses}

\section{Bivariate analysis}

In order to assess the site-level correlates of each type of nutritional support service, we conducted four separate 
bivariate analyses that focused on the reported availability of the following nutritional support services: (i) nutritional counselling (including general nutritional counselling for adults and infant feeding counselling for mothers); (ii) micronutrient supplementation (including multivitamin with or without mineral supplements, Fe supplements and vitamin A); (iii) treatment for severe malnutrition (including treatment of adults and children under 5 years of age); and (iv) food rations (including rations intended to promote adherence and household food security for adults and children). We examined correlates of the reported availability of each type of nutritional support service using the most recent survey data (July 2008) in relation to the following site-level covariates: time since the site's start of ART service provision ( $\leq 2 v$. $>2$ years before the survey); the cumulative number of individuals who had initiated ART by the time of the survey (dichotomized at the median of 260 patients); site location (rural $v$. urban); type of site (primary $v$. secondary or tertiary); reported presence of nutritionist on site (yes $v$. no); and reported availability of weight-for-height assessments (yes $v$. no).

\section{Multivariate analysis}

Multivariate logistic regression analyses were conducted to determine independent predictors of reported availability of each of the above-mentioned four nutritional support services. Variables with $P$ values $<0 \cdot 2$ in the bivariate analysis were included in the multivariate model. Thereafter, a backward selection procedure based on the Akaike Information Criterion was used to determine the final multivariate $_{\text {model }}{ }^{(37)}$. Model fit was assessed using the HosmerLemeshow statistic for determining goodness of $\mathrm{fit}^{(38)}$. Categorical explanatory variables were analysed using Pearson's $\chi^{2}$ and Fisher's exact tests and continuous variables were analysed using the Wilcoxon rank-sum test. All statistical analyses were performed using the SAS statistical software package version 9.1 (SAS Institute, Cary, NC, USA). All tests of significance were two-sided, with a cut-off $P$ value of 0.05 used to designate a statistically significant association.

\section{Time-trend analysis}

For the 174 sites for which three survey rounds had been completed, we examined changes in the reported availability of nutritional support services over the three time points during an 18-month period from January 2007 to July 2008. We assessed the prevalence of reported availability of each type of nutritional support service at each of the three survey time points (January 2007, July 2007 and July 2008). Statistical significance of changes in the prevalence of each type of service was assessed using the Cochran-Armitage trend test.

\section{Results}

Table 1 describes the location, site characteristics and prevalence of the reported availability of nutritional support services in the sample of $336 \mathrm{HIV}$ care and treatment sites in the nine sub-Saharan African countries. Of these, 185 (55\%) were situated in urban areas and 151 (45\%) in rural areas. By July 2008, these sites had cumulatively enrolled 467175 patients in HIV care and treatment (including 40430 (9\%) children and 429745 adults (91\%)), of whom 210019 individuals (45\%) had initiated ART (including 16507 (8\%) children and 193512 (92\%) adults). Of the 336 sites surveyed, 303 (90\%) reported the availability of at least one form of nutritional support service.

Among the 303 HIV care and treatment sites for which at least one form of nutritional support service was available, 140 (46\%) were primary care sites, 152 (50\%) were secondary care sites and eleven ( $4 \%)$ were tertiary care sites; twenty-one sites (7\%) had a nutritionist onsite and weight-for-height evaluation was available at 282 (93\%) sites. Among these 303 HIV care and treatment sites, the extent of availability of specific nutritional support services varied substantially (Fig. 1). Nutritional counselling was reported to be available at $98 \%$ of sites (range across countries (RAC): 94-100\%). Nutritional counselling for adults was reported to be available at 95\% of sites (RAC: $75-100 \%$ ) and infant feeding counselling for mothers with infants at 91\% (RAC: $81-100 \%$ ) of sites. Micronutrient supplementation was reported to be available at $64 \%$ of sites (RAC: $2-100 \%$ ) and multivitamin and mineral supplementation at 25\% (RAC: 0-97\%) of sites. Vitamin A supplementation to infants, postpartum women and other adults/non-infant children was reported to be available at 52\% (RAC: 2-89\%), $41 \%$ (RAC: 0-77\%) and 19\% (RAC: $0-58 \%$ ) of sites, respectively, and Fe supplementation was reported to be available at $47 \%$ (RAC: $0-89 \%)$ of sites. Treatment for severe malnutrition was reported to be available at $36 \%$ of sites (RAC: 0-72\%). Treatment for severely malnourished adults was reported to be available at $23 \%$ (RAC: $0-72 \%$ ) of sites and services for infants and children aged $<5$ years were available at 33\% (RAC: 0-69\%) of sites. Food rations were reported to be available at 31\% (RAC: 2-97\%) of sites, including rations for adults to promote medication adherence and household food security at 18\% (RAC: $0-87 \%$ ) and 4\% (RAC: 0-13\%) of sites, respectively. Food rations were reported to be available for children aged $<5$ years to promote medication adherence and household food security at 13\% (RAC: 0-77\%) and 7\% (RAC: 0-22\%) of sites, respectively.

In bivariate analysis (Table 2), nutritional counselling was more commonly reported to be available at secondary or tertiary care sites compared with primary care sites $(93 \% v .85 \%, P=0.026)$ and at sites where weight-for-height evaluation was available (98\% v. 39\%, $P<0 \cdot 001)$. Micronutrient supplementation was more commonly reported to be available in rural compared with urban sites $(65 \%$ v. $52 \%, P<0 \cdot 016)$ and at sites where weight-for-height evaluation was available $(65 \% v$. $17 \%, P<0 \cdot 001)$. Treatment for severe malnutrition was 
Table 1 Enrolment, clinical characteristics and location and prevalence of nutritional support service availability in 336 HIV care and treatment sites in sub-Saharan Africa, July 2008

\begin{tabular}{|c|c|c|c|c|c|c|c|}
\hline \multirow[b]{3}{*}{ Characteristic } & \multicolumn{7}{|c|}{ HIV care and treatment clinics } \\
\hline & \multicolumn{2}{|c|}{ Total } & \multicolumn{2}{|c|}{ Urban } & \multicolumn{2}{|c|}{ Rural } & \multirow[b]{2}{*}{$P$ value } \\
\hline & $n$ & $\%$ & $n$ & $\%$ & $n$ & $\%$ & \\
\hline HIV care and treatment sites & 336 & & 185 & 55 & 151 & 45 & \\
\hline \multicolumn{8}{|l|}{ Patients enrolled, $n$} \\
\hline Total patients enrolled & 467175 & & 398142 & & 69033 & & \\
\hline \multicolumn{6}{|l|}{ Patients receiving pre-ART care } & & \\
\hline Children ( $<15$ years) & 23923 & & 21093 & & 2830 & & \\
\hline Adults & 233233 & & 193460 & & 39773 & & \\
\hline \multicolumn{8}{|l|}{ Patients receiving ART care } \\
\hline All patients & 210019 & & 183589 & & 26430 & & \\
\hline Children ( $<15$ years) & 16507 & & 14642 & & 1865 & & \\
\hline Adults & 193512 & & 168947 & & 24565 & & \\
\hline \multicolumn{8}{|l|}{$\begin{array}{l}\text { HIV care and treatment sites with nutritional support services } \\
\text { available, } n \text { and } \%^{*}\end{array}$} \\
\hline 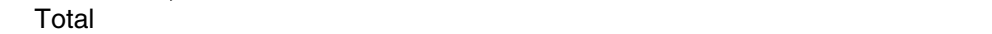 & 303 & 100 & 165 & 54 & 138 & 46 & \\
\hline \multicolumn{8}{|l|}{ Clinic type } \\
\hline Primary & 140 & 46 & 40 & 24 & 100 & 72 & $<0.001$ \\
\hline Secondary & 152 & 50 & 114 & 69 & 38 & 28 & \\
\hline Tertiary & 11 & 4 & 11 & 7 & - & - & \\
\hline Presence of nutritionist & 21 & 7 & 13 & 8 & 8 & 6 & 0.653 \\
\hline \multirow[t]{2}{*}{ Presence of weight-for-height evaluation } & 282 & 93 & 162 & 98 & 120 & 87 & $<0.001$ \\
\hline & $\%$ & Range & $\%$ & Range & $\%$ & Range & \\
\hline \multicolumn{8}{|l|}{$\begin{array}{l}\text { Type of nutritional support services available at HIV care and } \\
\text { treatment clinics, } n \text { and range across countries* }\end{array}$} \\
\hline Nutritional counselling & 98 & $94-100$ & 98 & $90-100$ & 99 & $91-100$ & 0.990 \\
\hline Nutritional counselling for adults & 95 & $75-100$ & 93 & $71-100$ & 99 & $96-100$ & 0.033 \\
\hline Infant feeding counselling for mothers & 91 & $81-100$ & 91 & $50-100$ & 92 & $82-100$ & $0 \cdot 888$ \\
\hline Micronutrient supplementation & 64 & $2-100$ & 58 & $3-100$ & 71 & $54-100$ & 0.028 \\
\hline Multivitamins and minerals supplementation & 25 & $0-97$ & 24 & $0-95$ & 25 & $0-100$ & 0.927 \\
\hline Vitamin A supplementation for infants & 52 & $2-89$ & 42 & 3-86 & 63 & $0-100$ & $<0.001$ \\
\hline Vitamin A supplementation for postpartum women & 41 & $0-77$ & 27 & $0-66$ & 57 & $0-100$ & $<0.001$ \\
\hline Vitamin A supplementation for other adults or non-infant children & 19 & $0-58$ & 11 & $0-30$ & 28 & $0-94$ & $<0.001$ \\
\hline Fe supplementation & 47 & $0-89$ & 38 & $0-86$ & 57 & $0-100$ & 0.001 \\
\hline Treatment for severe malnutrition & 36 & $0-72$ & 33 & $0-75$ & 39 & $0-100$ & 0.354 \\
\hline Nutritional treatment for adults & 23 & $0-72$ & 21 & $0-75$ & 26 & $0-100$ & $0 \cdot 351$ \\
\hline Nutritional treatment for infants and children aged $<5$ years & 33 & $0-69$ & 30 & $0-75$ & 36 & $0-94$ & $0 \cdot 332$ \\
\hline Food rations & 31 & 2-97 & 28 & $3-100$ & 36 & $0-96$ & $0 \cdot 193$ \\
\hline Formula feeding and weaning foods for infants & 22 & $0-75$ & 16 & $0-71$ & 29 & $0-100$ & 0.008 \\
\hline Food rations for adults to promote ART adherence & 18 & $0-87$ & 10 & $0-25$ & 28 & $0-88$ & $<0.001$ \\
\hline Food rations for adults to promote household food security & 4 & $0-13$ & 6 & $0-24$ & $0 \cdot 7$ & $0-6$ & 0.032 \\
\hline Food rations for children aged $<5$ years to promote ART adherence & 13 & $0-77$ & 7 & $0-75$ & 21 & $0-78$ & $<0.001$ \\
\hline Food rations for children aged $<5$ years to promote household food security & 7 & $0-22$ & 8 & $0-67$ & 7 & $0-31$ & $0 \cdot 845$ \\
\hline
\end{tabular}

more commonly reported to be available at sites providing ART services for over 2 years $(50 \% v .21 \%, P<0 \cdot 001)$, at sites that reported a nutritionist on staff $(57 \% v .31 \%$, $P=0.013)$ and at sites where weight-for-height evaluation was reported to be available $(38 \% v .4 \%, P<0 \cdot 001)$. The reported availability of food rations was higher at sites providing ART for at least 2 years (45\% v. 18\%, $P<0 \cdot 001)$ and at sites where weight-for-height evaluation was reported to be available $(33 \% v .2 \%, P<0 \cdot 001)$.

In multivariate analysis (Table 3 ), secondary or tertiary care sites were associated with a higher odds of nutritional counselling availability (adjusted OR (AOR)

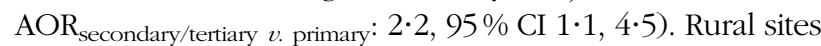
(AOR rural $v$. urban: $2 \cdot 3,95 \% \mathrm{CI} 1 \cdot 4,3 \cdot 8)$ and sites where weight-

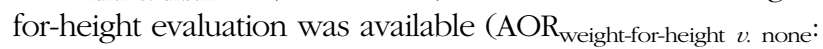

$11 \cdot 0,95 \%$ CI $5 \cdot 0,24 \cdot 0)$ reported higher odds of micronutrient supplementation availability. Sites that had provided ART for at least 2 years had a higher odds of having treatment for severe malnutrition $\left(\mathrm{AOR}_{\geq 2}\right.$ years $v .<2$ years: $2 \cdot 4,95 \%$ CI $1 \cdot 4,4 \cdot 1)$. Sites that had provided ART for a minimum of 2 years $\left(\mathrm{AOR}_{\geq 2}\right.$ years $v,<2$ years: $1 \cdot 6,95 \% \mathrm{CI}$

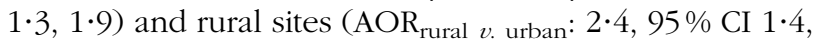
$4 \cdot 4$ ) had greater odds of reported availability of food rations.

Of the 336 sites, 174 (52\%) had information available from the three consecutive PFaCTS surveys (January 2007, July 2007 and July 2008) and were included in the timetrend analysis. Over the 18-month period, micronutrient supplementation and treatment for severe malnutrition became increasingly more common. The percentage of 


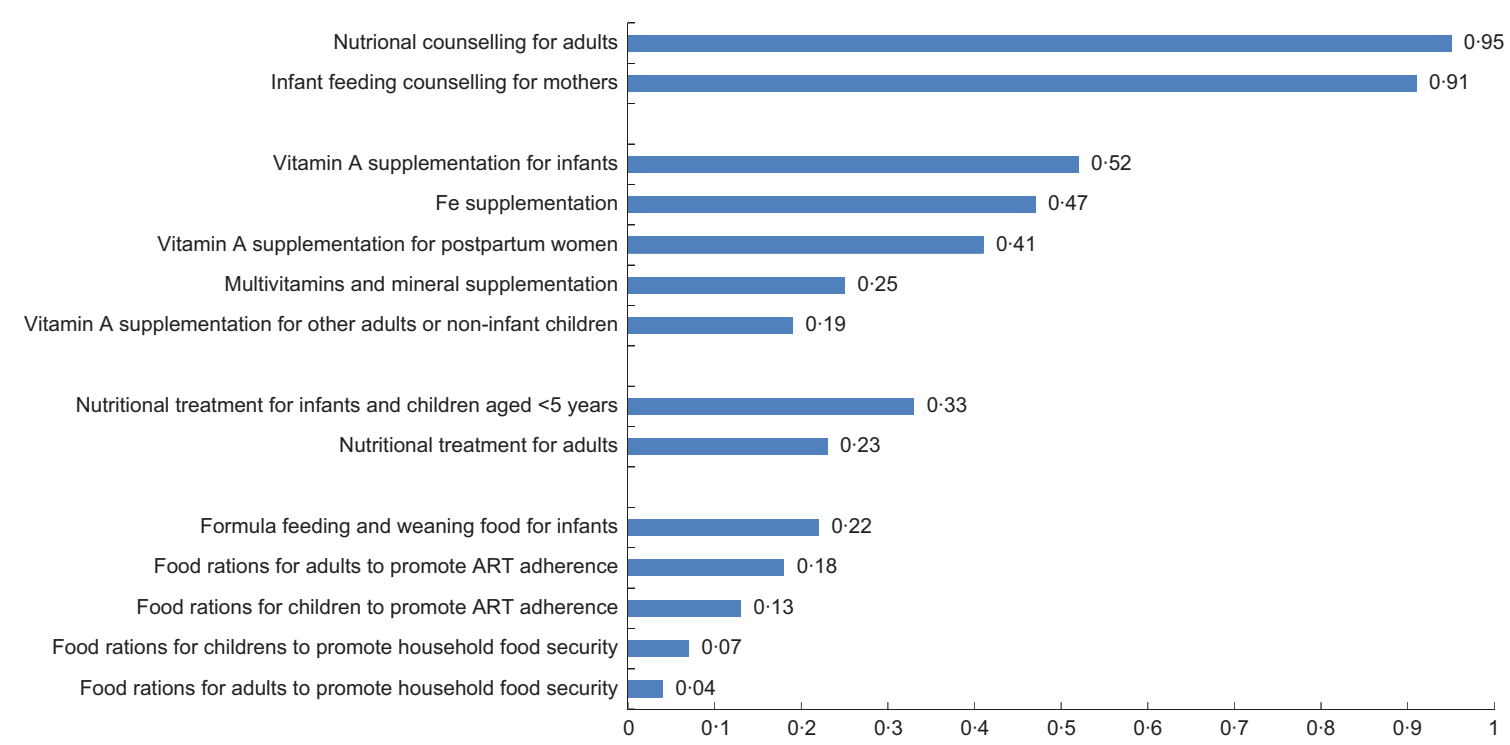

Fig. 1 Prevalence of nutritional support services available in 303 HIV care and treatment sites in nine sub-Saharan African countries, July 2008 (ART, antiretroviral therapy)

sites with availability of micronutrient supplementation increased from $19 \%$ in January 2007 to $56 \%$ in July 2008 $(P<0 \cdot 001)$. Similarly, the percentage of sites with availability of treatment for severely malnourished individuals also increased significantly (from 24\% in January 2007 to $40 \%$ in July 2008, $P=0 \cdot 001$ ). No significant trend was detected in the availability of nutritional counselling $(P=0 \cdot 86)$ or food rations $(P=0 \cdot 08)$, although the prevalence of the former was already high (87\%) in January 2007. In order to verify that no bias resulted from the exclusion of sites without three consecutive surveys, we re-ran the time-trend analysis including all sites. This analysis similarly found a significant increase in the availabilities of micronutrient supplementation $(P<0 \cdot 001)$ and treatment for severe malnutrition $(P=0 \cdot 006)$ and no significant trend for other nutritional support services.

\section{Discussion}

This investigation evaluated the prevalence and correlates of the reported availability of different types of nutritional support services in HIV care and treatment sites in multiple sub-Saharan African countries. Ninety per cent of sites had at least one form of nutritional support service. However, the type of nutritional support services reported to be available varied substantially, including by country, geographical context (urban/rural) and site-level characteristics (type of site, age of programme, reported presence of a nutritionist on staff).

The fact that nutritional counselling to adults and to pregnant and lactating mothers was reported to be available at $95 \%$ and $91 \%$ of sites, respectively, is encouraging. Nutritional counselling is considered to be a cornerstone of HIV treatment support, recommended by multiple international guidelines ${ }^{(36,39,40)}$. Nutritional counselling is also important for supporting HIV-affected households. Studies in sub-Saharan Africa have found that HIV-exposed but uninfected children have poorer growth compared with HIV-uninfected children, possibly because of reduced breast-feeding practices by HIV-infected mothers ${ }^{(41)}$. Exposure to nutritional counselling and education about safe breast-feeding practices is associated with increased weight gain and a reduced risk of postnatally acquired HIV infection among HIV-exposed infants, respectively ${ }^{(42,43)}$. Sustained programme efforts and optimization of general and infant feeding counselling are critical, particularly as rates of exclusive breast-feeding among HIV-infected mothers remain low in many settings where it is recommended ${ }^{(44)}$.

Although some type of micronutrient supplementation was reported to be available at $64 \%$ of sites, this mostly included vitamin A and Fe supplementation. The fact that multivitamin and mineral supplementation was reported to be available at only $25 \%$ of HIV care and treatment sites suggests that there is room for improvement. Studies have found that many people living with HIV/AIDS suffer various micronutrient deficiencies and have increased micronutrient needs ${ }^{(45)}$. However, evidence of the effectiveness of micronutrient supplementation on HIV-infected adults and children remains limited, and findings have been heterogeneous. Supplementation of specific vitamins and minerals has been associated with several clinical benefits among people living with HIV/AIDS, including reduced risk of hospitalization ${ }^{(46)}$, increased CD 4 cell count levels ${ }^{(47)}$ and reductions in all-cause mortality ${ }^{(48)}$. Among individuals receiving ART, micronutrient supplementation has been variously correlated with improved immunological, 
Table 2 Bivariate analysis of factors associated with availability of nutritional counselling, micronutrient supplementation, treatment for severe malnutrition and food rations to people living with HIV/AIDS in HIV care and treatment sites in nine sub-Saharan African countries, July 2008 ( $n$ 336)

\begin{tabular}{|c|c|c|c|c|c|c|c|c|c|c|c|c|c|c|c|c|c|c|c|c|}
\hline \multirow[b]{3}{*}{ Characteristic } & \multicolumn{5}{|c|}{ Nutritional counselling } & \multicolumn{5}{|c|}{ Micronutrient supplementation } & \multicolumn{5}{|c|}{ Treatment for severe malnutrition } & \multicolumn{5}{|c|}{ Food rations } \\
\hline & \multicolumn{2}{|c|}{ No $(n 38)$} & \multicolumn{2}{|c|}{ Yes $(n$ 298) } & \multirow[b]{2}{*}{$P$ value } & \multicolumn{2}{|c|}{ No $(n$ 142) } & \multicolumn{2}{|c|}{ Yes $(n 194)$} & \multirow[b]{2}{*}{$P$ value } & \multicolumn{2}{|c|}{ No $(n$ 227) } & \multicolumn{2}{|c|}{ Yes $(n$ 109) } & \multirow[b]{2}{*}{$P$ value } & \multicolumn{2}{|c|}{ No } & \multicolumn{2}{|c|}{ Yes } & \multirow[b]{2}{*}{$P$ value } \\
\hline & $n$ & $\%$ & $n$ & $\%$ & & $n$ & $\%$ & $n$ & $\%$ & & $n$ & $\%$ & $n$ & $\%$ & & $n$ & $\%$ & $n$ & $\%$ & \\
\hline \multicolumn{21}{|l|}{ Programme age } \\
\hline $\begin{array}{l}\leq 2 \text { years } \\
>2 \text { vears }\end{array}$ & 22 & $10 \cdot 7$ & 184 & $89 \cdot 3$ & \multirow[t]{2}{*}{0.646} & 92 & $44 \cdot 7$ & 114 & $55 \cdot 3$ & \multirow[t]{2}{*}{0.263} & 162 & $78 \cdot 6$ & 44 & $21 \cdot 4$ & \multirow{2}{*}{$<0.001$} & 169 & $82 \cdot 0$ & 37 & $18 \cdot 0$ & \multirow[t]{2}{*}{$<0.001$} \\
\hline \multicolumn{14}{|c|}{ Number of people on ART } & & & & $55 \cdot 4$ & 58 & $44 \cdot 6$ & \\
\hline$\leq 260$ & 11 & $9 \cdot 5$ & 105 & $90 \cdot 5$ & \multirow[t]{2}{*}{0.983} & 47 & $40 \cdot 5$ & 69 & $59 \cdot 5$ & \multirow[t]{2}{*}{0.648} & 76 & $65 \cdot 5$ & 40 & 34.5 & \multirow[t]{2}{*}{0.096} & 76 & $65 \cdot 5$ & 40 & 34.5 & \multirow[t]{2}{*}{0.927} \\
\hline$>260$ & 11 & $9 \cdot 6$ & 104 & $90 \cdot 4$ & & 50 & $43 \cdot 5$ & 65 & $56 \cdot 5$ & & 63 & $54 \cdot 8$ & 52 & $45 \cdot 2$ & & 76 & $66 \cdot 1$ & 39 & 33.9 & \\
\hline \multicolumn{21}{|l|}{ Location } \\
\hline Rural & 15 & $9 \cdot 9$ & 136 & $90 \cdot 1$ & \multirow[t]{2}{*}{0.472} & 53 & $35 \cdot 1$ & 98 & $64 \cdot 9$ & \multirow[t]{2}{*}{0.016} & 97 & $64 \cdot 2$ & 54 & $35 \cdot 8$ & 0.24 & 102 & $67 \cdot 6$ & 49 & $32 \cdot 4$ & 0.125 \\
\hline Urban & 23 & $12 \cdot 4$ & 162 & $87 \cdot 6$ & & 89 & $48 \cdot 1$ & 96 & $51 \cdot 9$ & & 130 & $70 \cdot 3$ & 55 & $29 \cdot 7$ & & 139 & $75 \cdot 1$ & 46 & 24.9 & \\
\hline Type of site & & & & & & & & & & & & & & & & & & & & \\
\hline $\begin{array}{l}\text { Primary } \\
\text { Secondary/tertiary }\end{array}$ & 24 & $15 \cdot 1$ & 135 & $85 \cdot 0$ & 0.026 & 58 & $36 \cdot 5$ & 101 & $63 \cdot 5$ & 0.055 & 106 & $66 \cdot 7$ & 53 & $33 \cdot 3$ & 0.795 & 107 & $67 \cdot 3$ & 52 & $32 \cdot 7$ & $0 \cdot 100$ \\
\hline $\begin{array}{l}\text { Secondary/tertiary } \\
\text { Presence of nutrition }\end{array}$ & 13 & 4 & 162 & $92 \cdot 6$ & & 82 & 46 & 93 & $53 \cdot 1$ & & 119 & 6 & 56 & $32 \cdot 0$ & & 132 & $75 \cdot 4$ & 43 & $24 \cdot 6$ & \\
\hline No & 38 & $12 \cdot 1$ & 277 & $87 \cdot 9$ & 0.148 & 135 & 42.9 & 180 & $57 \cdot 1$ & 0.392 & 218 & $69 \cdot 2$ & 97 & $30 \cdot 8$ & 0.013 & 228 & $72 \cdot 4$ & 87 & $27 \cdot 6$ & 0.302 \\
\hline Yes & 0 & 0.0 & 21 & $100 \cdot 0$ & & 7 & $33 \cdot 3$ & 14 & $66 \cdot 7$ & & 9 & $42 \cdot 9$ & 12 & $57 \cdot 1$ & & 13 & 61.9 & 8 & $38 \cdot 1$ & \\
\hline $\begin{array}{l}\text { Weight-for-height eva } \\
\text { No }\end{array}$ & 32 & $61 \cdot 5$ & 20 & 38.5 & $<0.001$ & 43 & $82 \cdot 7$ & 9 & $17 \cdot 3$ & $<0.001$ & 50 & $96 \cdot 2$ & 2 & 3.8 & $<0.001$ & 51 & $98 \cdot 1$ & 1 & 1.9 & $<0.001$ \\
\hline Yes & 6 & $2 \cdot 1$ & 278 & 97.9 & & 99 & 34.9 & 185 & $65 \cdot 1$ & & 177 & $62 \cdot 3$ & 107 & 37.7 & & 190 & 66.9 & 94 & $33 \cdot 1$ & \\
\hline
\end{tabular}

ART, antiretroviral therapy.

Table 3 Multivariate analysis of factors associated with availability of nutritional counselling, micronutrient supplementation, treatment for severe malnutrition and food rations to people living with HIV/AIDS in HIV care and treatment sites in nine sub-Saharan African countries, July 2008

\begin{tabular}{|c|c|c|c|c|c|c|c|c|c|c|c|c|c|c|c|c|}
\hline \multirow[b]{3}{*}{ Characteristic } & \multicolumn{4}{|c|}{ Nutritional counselling } & \multicolumn{4}{|c|}{ Micronutrient supplementation } & \multicolumn{4}{|c|}{ Treatment for severe malnutrition } & \multicolumn{4}{|c|}{ Food rations } \\
\hline & \multicolumn{2}{|c|}{ Unadjusted } & \multicolumn{2}{|c|}{ Adjusted } & \multicolumn{2}{|c|}{ Unadjusted } & \multicolumn{2}{|c|}{ Adjusted } & \multicolumn{2}{|c|}{ Unadjusted } & \multicolumn{2}{|c|}{ Adjusted } & \multicolumn{2}{|c|}{ Unadjusted } & \multicolumn{2}{|c|}{ Adjusted } \\
\hline & OR & $95 \% \mathrm{Cl}$ & OR & $95 \% \mathrm{Cl}$ & OR & $95 \% \mathrm{Cl}$ & OR & $95 \% \mathrm{Cl}$ & OR & $95 \% \mathrm{Cl}$ & OR & $95 \% \mathrm{Cl}$ & OR & $95 \% \mathrm{Cl}$ & OR & $95 \% \mathrm{Cl}$ \\
\hline Programme age & & & & & & & & & & & & & & & & \\
\hline $\begin{array}{l}>2 \text { years } v . \leq 2 \text { years } \\
\text { Number of people on ART }\end{array}$ & $0 \cdot 85$ & $0.43,1 \cdot 69$ & - & - & $1 \cdot 29$ & $0 \cdot 83,2 \cdot 02$ & - & - & $3 \cdot 68$ & $2 \cdot 28,5 \cdot 94$ & $2 \cdot 37$ & $1 \cdot 37,4 \cdot 10$ & 3.68 & $2 \cdot 24,6 \cdot 04$ & 1.57 & $1 \cdot 32,1 \cdot 88$ \\
\hline $\begin{array}{l}>260 \text { v. } \leq 260 \\
\text { Location }\end{array}$ & 0.99 & $0 \cdot 41,2 \cdot 39$ & - & - & $0 \cdot 89$ & $0.53,1.49$ & - & - & $1 \cdot 57$ & $0.92,2 \cdot 67$ & - & - & 0.98 & $0.57,1.68$ & - & - \\
\hline $\begin{array}{l}\text { Rural } v \text {. urban } \\
\text { Type of site }\end{array}$ & $1 \cdot 29$ & $0 \cdot 65,2.56$ & - & - & $1 \cdot 71$ & $1 \cdot 10,2 \cdot 67$ & $2 \cdot 29$ & $1 \cdot 40,3 \cdot 75$ & $1 \cdot 32$ & $0 \cdot 83,2 \cdot 08$ & - & - & $1 \cdot 45$ & $0.90,2.34$ & $2 \cdot 44$ & $1 \cdot 41,4 \cdot 22$ \\
\hline $\begin{array}{l}\text { Secondary/tertiary } v \text {. } \\
\text { primary }\end{array}$ & 0.45 & $0.22,0.92$ & $2 \cdot 2$ & $1 \cdot 1,04 \cdot 5$ & $1 \cdot 50$ & $0 \cdot 99,2 \cdot 40$ & - & - & $1 \cdot 06$ & $0.67,1.68$ & - & - & $1 \cdot 49$ & $0 \cdot 93,2 \cdot 41$ & - & - \\
\hline $\begin{array}{l}\text { Presence of nutritionist } \\
\text { Yes } v \text {. no } \\
\text { Weight-for-height evaluation }\end{array}$ & - & - & - & - & $1 \cdot 50$ & $0 \cdot 59,3 \cdot 82$ & - & - & $2 \cdot 99$ & $1 \cdot 22,7 \cdot 35$ & - & - & $1 \cdot 61$ & $0.65,4.03$ & - & - \\
\hline Yes $v$. no & - & - & - & - & $8 \cdot 93$ & $4 \cdot 18,19 \cdot 07$ & $10 \cdot 97$ & $5 \cdot 00,24 \cdot 07$ & - & - & - & - & - & - & - & - \\
\hline
\end{tabular}

ART, antiretroviral therapy. 
virological and clinical status and may facilitate decreases in mitochondrial dysfunction, oxidative stress and metabolic complexities ${ }^{(49)}$. A recent meta-analysis found that periodic vitamin A supplementation of HIV-positive children aged $>6$ months was associated with reduced all-cause mortality, but additional research is required to determine the impact on HIV-infected adults ${ }^{(48)}$. Results from studies evaluating the impact of other specific micronutrients, such as vitamin E, Se, Zn and Fe, on HIVinfected individuals remain inconclusive ${ }^{(45)}$. Although the reported availability of micronutrient supplementation at some of the HIV care and treatment sites in our sample is encouraging, the expansion of access to micronutrient supplementation must be evidence-informed via research studies, with scale-up, safety and adherence carefully monitored at site and patient levels to ensure optimal outcomes.

Food rations were reported to be available at $31 \%$ of HIV care and treatment sites. Macronutrient supplementation, commonly comprising corn-soya blend, fortified blended foods and high-energy ready-to-use therapeutic foods (RUTF), is often used as a replacement of, or complement to, regular staple foods ${ }^{(50)}$. Supplemental feeding is often used to mitigate the impacts of mild and moderate malnutrition and to prevent further deterioration of nutritional status to severe acute malnutrition.

Studies have noted that provision of food rations may be associated with improved medication adherence and retention in HIV care and treatment in sub-Saharan Africa, which is both a major and persistent challenge of scale-up in the region ${ }^{(51,52)}$. In a qualitative programme evaluation from Kenya, provision of household food rations to foodinsecure individuals on ART improved treatment adherence, reduced drug-related side effects and increased appetite satisfaction, weight gain and physical strength ${ }^{(53)}$. A randomized controlled trial involving 636 food-insecure adults starting ART in Zambia found that individuals who received home-based WFP rations were 1.5 times more likely to achieve 95\% ART adherence, compared with the control group ${ }^{(54)}$. Finally, we reported in a previous ecological analysis of 108056 individuals initiating ART across ten sub-Saharan African countries that the reported availability of food supplementation was significantly associated with higher retention in HIV care and treatment ${ }^{(55)}$. The impact of fortified food supplementation on HIV-affected individuals is varied. A randomized controlled trial in Zambia comparing the impact of a basal $v$. micronutrient-fortified infant porridge in Zambia found that micronutrient supplementation did not reduce stunting or hospital referrals among HIV-exposed children but did improve Fe status and anaemia ${ }^{(56)}$. Given the high burden of food insecurity in sub-Saharan Africa ${ }^{(6)}$, availability of food supplementation in HIV care and treatment sites to HIV-infected and -affected individuals could promote individual and household food security and clinical outcomes.
Treatment for severe malnutrition was reported to be available at $36 \%$ of HIV care and treatment sites and was more likely to be reported to be available at sites that had been providing ART for more than 2 years. This may be because longer established ART sites have increased logistic capacity, compared with more recently established ART sites ${ }^{(57)}$. Interestingly, the likelihood of reported availability of treatment for severe malnutrition was similar at primary, secondary and tertiary care sites. This finding is surprising given that, until recently, the WHO clinical guidelines recommended in-patient hospital admission and prescription of high-energy milk products for the treatment for severe acute malnutrition. Operations research in sub-Saharan Africa now suggests that community-based distribution of RUTF is just as feasible and safe as, and more cost-effective than, hospital-based rehabilitation ${ }^{(58)}$. Our findings that availability of treatment for severe malnutrition has expanded significantly even over a $1 \cdot 5$-year period suggest that ART treatment and care sites may be distributing RUTF products. These findings are promising given that RUTF use has been associated with rapid weight gain, improvements in physical activity and increased uptake of VCT and ART services among HIV-positive individuals with severe acute malnutrition ${ }^{(59,60)}$.

Our study has several strengths and limitations. The strengths of our study include the large number of sites, which allowed us to conduct an analysis of the reported availability of nutritional support services in scale-up programmes across several sub-Saharan African countries and settings. We were also able to include rural sites and primary health centres, increasing the generalizability of the findings. All PEPFAR-supported HIV care and treatment sites are situated within the public sector and as such are representative of African countries' national efforts to scale-up ART access. Although the sites included in our sample are likely not representative of all HIV clinics in the region or within each country, they represent primary, secondary and tertiary scale-up sites from a diverse array of settings and contexts. These sites represent a substantial proportion of all patients initiating ART in sub-Saharan Africa, including over $7 \%$ of the estimated 2.925 million people receiving ART in the continent in $2008^{(61)}$.

The study survey tool was formally tested for reliability and accuracy and was found to have a good level of reliability between staff- and supervisory-completed responses. The following data management systems likely contributed to this high level of agreement, and additionally contributed to consistency of data quality across study sites and countries: (i) responses to surveys were recorded following a process of discussion and consensus among site staff; (ii) surveys were administered at sites using standard operating procedures, with reference to clearly defined indicators; and (iii) all data were computerrecorded using automated data entry controls and logic checks, followed by systematic data cleaning. 
A major limitation is that site surveys solicited information only about the availability of different types of services and did not ascertain the access, quality, comprehensiveness or coverage of the indicated services at the sites. Thus, no information is available on the actual number, proportion or subsets of patients who utilized these services. For example, although the proportion of sites that reported availability of nutritional counselling or weight-for-height evaluation was high, we could not assess the proportion of patients who actually received these services at the sites in our sample ${ }^{(62)}$. The amount of micronutrient supplementation available to clients at each site was unknown, and likely varied given the differences between the $\mathrm{WHO}$ and regional recommendations for recommended nutrient intake ${ }^{(45)}$. We were unable to assess what types of food rations were available and whether these were intended for use by all HIV-positive individuals, by specific groups of HIV-infected groups or by HIV-affected households. Finally, we were unable to ascertain the types of treatment that were available for severe malnutrition and the extent to which RUTF products may have contributed to rapid increases in availability. Consequently, these data are most useful for macro-level policy and programmatic planning.

Our study is in alignment with the United Nations General Assembly Special Session (UNGASS) Declaration of Commitment on HIV/AIDS' goal of monitoring and evaluating process outputs from HIV treatment and care facilities ${ }^{(63)}$. These findings can directly assist national Ministries of Health and their partners' efforts to monitor the rollout of HIV-related support services in accordance with national policies, to identify time-bound national goals for improving support to people living with HIV/AIDS and to track changes in the availability of these services over time $^{(63)}$. UNGASS 2010 Guidelines on the Construction of Core Indicators failed to explicitly recommend the collection of national programme indicators on nutritional support to adults and children living with HIV/AIDS and their affected households ${ }^{(64)}$. Cross-national health facility data on the availability of nutritional support services are essential to effectively monitor and evaluate global HIV treatment and care outcomes.

\section{Conclusion}

Basic nutritional support services were reported to be available at a large number of public sector HIV care and treatment sites across urban and rural settings in several sub-Saharan African countries. Reported availability of specific nutritional support services varies by country, geographical context and clinical or programme characteristics. These findings can inform Ministries of Health and their partners in their efforts to make these services available at sites that provide HIV care and treatment in accordance with national policies ${ }^{(63)}$. Expansion of availability of nutritional services is of critical importance. Further efforts are urgently needed to determine, in addition to availability, the uptake, quality and effectiveness of these services and their impact on programme outcomes such as adherence to ART, retention in care and survival.

\section{Acknowledgements}

International Center for AIDS Care and Treatment Programs (ICAP)-supported HIV prevention, care and treatment programmes are funded through the President's Emergency Plan for AIDS Relief. The present research was supported by the Doris Duke Charitable Foundation's Operations Research on AIDS Care and Treatment in Africa. A.A. is supported by the Canadian Institutes of Health Research. R.S.H. has received grant funding from the National Institutes of Health, Canadian Institutes of Health Research National Health Research Development Program and Health Canada. He has also received funding from Agouron Pharmaceuticals Inc., Boehringer Ingelheim Pharmaceuticals Inc., Bristol-Myers Squibb, GlaxoSmithKline and Merck Frosst Laboratories for participating in continued medical education programmes. J.S.G.M. has received grants from, served as an ad hoc advisor to, or spoken at various events sponsored by Abbott, Argos Therapeutics, Bioject Inc., Boehringer Ingelheim, BMS, Gilead Sciences, GlaxoSmithKline, Hoffmann-La Roche, Janssen-Ortho, Merck Frosst, Pfizer, Schering, Serono Inc., TheraTechnologies, Tibotec and Trimeris. He has also received grant funding from the Canadian Institutes of Health Research and National Institutes of Health and for research and continuing medical education programmes from a number of pharmaceutical companies including Abbott, Boehringer Ingelheim and GlaxoSmithKline. The funders had no role in study design, data collection and analysis, nor in the decision to publish or in preparation of the manuscript. The authors have no conflict of interest to declare. A.A. and D.N. conceived of the study aims, objectives and overall study design; A.A., D.N., W.Z. and Y.W. developed the study methodologies; A.A., W.Z. and D.N. wrote the first draft of the manuscript; R.S.H., J.S.G.M., S.W., B.E. and W.E.-S. contributed technical expertise and critically reviewed manuscript drafts; D.N. oversaw all aspects of the study design, as well as survey data collection and data management. The authors thank the headquarters and field staff from the International Center for AIDS Care and Treatment Programs who completed the Program and Facility Characteristics Tracking System survey, including the following staff: Dr Caroline Korves, Ms Suzue Saito, Ms May Tun and Mr Matthew Lamb from the ICAP Headquarters in New York, USA; Senior Monitoring and Evaluation Advisors in the ICAP country offices, including Dr Tsigereda Gadisa (ICAP Ethiopia), Dr Muhsin Sheriff (ICAP Kenya), 
Ms Melanie Manyasha (ICAP Lesotho), Ms Maria Fernanda Alvim (ICAP Mozambique), Mr Frank Oransaye (ICAP Nigeria), Dr Veronicah Mugisha (ICAP Rwanda), Dr Harriet Nuwagaba-Biribonwoha (ICAP Tanzania), Ms Kanchan Reid (ICAP South Africa) and Mr Hermann Brou (ICAP Cote d'Ivoire); ICAP Clinical Officers in each country who contributed to data collection; and ICAP Country Directors Dr Mark Hawken (ICAP Kenya), Dr Zenebe Melaku (ICAP Ethiopia), Ms Amy Cunningham (ICAP Tanzania), Dr Ruben Sahabo (ICAP Rwanda), Dr Tshiwela Neluheni (ICAP South Africa), Dr Bolanle Oyeledun (ICAP Nigeria), Dr Raphael Ntumy (ICAP Lesotho), Dr Josue Lima (ICAP Mozambique) and Dr Ida Viho (ICAP Cote d'Ivoire) for overall support and guidance. The authors also acknowledge the Ministries of Health from Kenya, Tanzania, Ethiopia, Rwanda, Mozambique, South Africa, Nigeria, Lesotho and Cote d'Ivoire whose HIV care and treatment programmes they endeavoured to support through the present work. Finally, they also thank Dr David Hoos for overall leadership on programme activities.

\section{References}

1. Joint United Nations Programme on HIV/AIDS (2010) UNAIDS report on the global AIDS epidemic. http:// www.unaids.org/documents/20101123_GlobalReport_em.pdf (accessed July 2011).

2. Hogg RS, Heath KV, Yip B et al. (1998) Improved survival among HIV-infected individuals following initiation of antiretroviral therapy. JAMA 279, 450-454.

3. Hogg RS, Yip B, Chan KJ et al. (2001) Rates of disease progression by baseline CD4 cell count and viral load after initiating triple-drug therapy. JAMA 286, 2568-2577.

4. Lima VD, Hogg RS, Harrigan PR et al. (2007) Continued improvement in survival among HIV-infected individuals with newer forms of highly active antiretroviral therapy. AIDS 21, 685-692.

5. World Health Organization (2010) Towards Universal Access: scaling up priority HIV/AIDS interventions in the health sector: progress report. http://whqlibdoc.who.int/ publications/2010/9789241500395_eng.pdf (accessed July 2011).

6. United Nations Food and Agriculture Organization (2010) The state of food insecurity in the world: addressing food insecurity in protracted crises. http://www.fao.org/docrep/ 013/i1683e/i1683e.pdf (accessed July 2011).

7. World Food Programme, World Health Organization, Joint United Nations Programme on HIV/AIDS (2008) HIV, food security and nutrition: policy brief expanded version. http://www.data.unaids.org/pub/.../2008/jc1565_policy_brief_ nutrition_long_en.pdf (accessed July 2011).

8. United Nations Administrative Committee on Coordination Sub-Committee on Nutrition (2000) Fourth Report on the World Nutrition Situation: Nutrition Throughout the Lifecycle. Geneva: ACC/SCN; available at: http://www.unscn. org/layout/modules/resources/files/rwns4.pdf/

9. Ahoua L, Umutoni C, Huerga $\mathrm{H}$ et al. (2011) Nutrition outcomes of HIV-infected malnourished adults treated with ready-to-use therapeutic food in sub-Saharan Africa: a longitudinal study. J Int AIDS SOC 14, 1-9.

10. Uthman OA (2008) Prevalence and pattern of HIV-related malnutrition among women in sub-Saharan Africa: a meta analysis of demographic health surveys. BMC Public Health 8, 226.
11. Magadi MA (2011) Cross-national analysis of the risk factors of child malnutrition among children made vulnerable by HIV/AIDS in sub-Saharan Africa: evidence from the DHS. Trop Med Int Health 16, 570-578.

12. Gillespie S \& Kadiyala S (2005) HIV/AIDS and Food and Nutrition Security: From Evidence to Action. Washington, DC: IFPRI.

13. Bukusuba J, Kikafunda JK \& Whitehead RG (2007) Food security status in households of people living with HIV/ AIDS (PLWHA) in a Ugandan urban setting. Br J Nutr $\mathbf{9 8}$, 211-217.

14. Food and Nutrition Technical Assistance (2007) Recommendation for the nutrient requirements for people living with HIV/AIDS. www.fantaproject.org/.../Nutrient_Requirements_ HIV_Feb07.pdf (accessed July 2011).

15. World Food Programme (2003) Programming in the era of AIDS: WPF's response to HIV/AIDS. http://www.wfp.org/ sites/default/files/Programming\%20in\%20the\%20Era\%20of \%20AIDS\%20WFP's\%20Response\%20to\%20HIV:AIDS.pdf (accessed July 2011).

16. Salomon J, de Truchis P \& Melchior JC (2002) Body composition and nutritional parameters in HIV and AIDS patients. Clin Chem Lab Med 40, 1329-1333.

17. Kotler DP, Tierney AR, Brenner SK et al. (1990) Preservation of short-term energy balance in clinically stable patients with AIDS. Am J Clin Nutr 51, 7-13.

18. Mangili A, Murman SH, Zampini M et al. (2006) Nutrition and HIV infection: review of weight loss and wasting in the era of highly active antiretroviral therapy from the nutrition for healthy living cohort. Clin Infect Dis 42, 836-842.

19. Grinspoon S \& Mulligan K (2003) Weight loss and wasting in patients infected with human immunodeficiency virus. Clin Infect Dis 36, 69-78.

20. Boffito M, Acosta E, Burger D et al. (2005) Therapeutic drug monitoring and drug-drug interactions involving antiretroviral drugs. Antivir Ther 10, 469-477.

21. Mshana GH, Wamoyi J, Busza J et al. (2006) Barriers to accessing antiretroviral therapy in Kisesa, Tanzania: a qualitative study of early rural referrals to the national program. AIDS Patient Care STDS 20, 649-657.

22. Tuller DM, Bangsberg DR, Senkungu J et al. (2010) Transportation costs impede sustained adherence and access to HAART in a clinic population in southwestern Uganda: a qualitative study. AIDS Behav 14, 778-784.

23. Au JT, Kayitenkore K, Shutes E et al. (2006) Access to adequate nutrition is a major potential obstacle to antiretroviral adherence among HIV-infected individuals in Rwanda. AIDS 20, 2116-2118.

24. Sanjobo N, Frich JC \& Fretheim A (2008) Barriers and facilitators to patients' adherence to antiretroviral treatment in Zambia: a qualitative study. SAHARA J 5, 136-143.

25. Weiser SD, Fernandes K, Anema A et al. (2009) Food insecurity as a barrier to antiretroviral therapy (ART) adherence among HIV-infected individuals. Presented at 5th International AIDS Society (IAS) Conference on HIV Pathogenesis, Treatment and Prevention, Cape Town, South Africa, 19-22 July 2009.

26. Normén L, Chan K, Braitstein P et al. (2005) Food insecurity and hunger are prevalent among HIV-positive individuals in British Columbia, Canada. J Nutr 135, 820-825.

27. Weiser SD, Frongillo EA, Ragland $\mathrm{K}$ et al. (2008) Food insecurity is associated with incomplete HIV RNA suppression among homeless and marginally housed HIV-infected individuals in San Francisco. J Gen Intern Med 24, 14-20.

28. Weiser SD, Bangsberg DR, Kegeles S et al. (2009) Food insecurity among homeless and marginally housed individuals living with HIV/AIDS in San Francisco. AIDS Behav 13, 841-848.

29. Weiser SD, Fernandes F, Brandson EK et al. (2009) The impact of food insecurity and body mass index on mortality 
among HIV-infected individuals first initiating HAART. J Acquir Immune Defic Syndr 52, 342-349.

30. Stringer JS, Zulu I, Levy J et al. (2006) Rapid scale-up of antiretroviral therapy at primary care sites in Zambia: feasibility and early outcomes. JAMA 296, 782-793.

31. Zachariah R, Fitzgerald M, Massaquoi M et al. (2006) Risk factors for high early mortality in patients on antiretroviral treatment in a rural district of Malawi. AIDS 20, 2355-2360.

32. Johannessen A, Naman E, Ngowi BJ et al. (2008) Predictors of mortality in HIV-infected patients starting antiretroviral therapy in a rural hospital in Tanzania. BMC Infect Dis $\mathbf{8}, 52$.

33. President's Emergency Plan for AIDS Relief (2009) PEPFAR policy change in food and nutrition programming. http:// www.pepfar.gov/guidance/98836.htm (accessed July 2011).

34. President's Emergency Plan for AIDS Relief (2010) Country operational plan (COP) guidance: fiscal year 2011. http:// www.pepfar.gov/documents/organization/148826.pdf (accessed July 2011).

35. World Health Organization (2003) Nutrient requirements for people living with HIV/AIDS. Report of a technical consultation. http://www.who.int/nutrition/publications/ Content_nutrient_requirements.pdf (accessed July 2011).

36. Food and Nutrition Technical Assistance (2004) HIV/AIDS: a guide for nutritional care and support. http://www.fantaproject. org/publications/HIVguide.shtml (accessed June 2009).

37. Lachin JM (2000) Biostatistical Methods: The Assessment of Relative Risks. New York: John Wiley Publishing.

38. Hosmer D Jr \& Lemeshow S (2000) Applied Logistic Regression, 2nd ed. New York: John Wiley Publishing.

39. World Health Organization (2004) Nutrition counseling, care and support for HIV-infected women: guidelines on HIV-related care, treatment and support for HIV-infected women and their children in resource constrained settings. http://www.who.int/hiv/pub/prev_care/nutrition/en/index. html (accessed June 2009).

40. Médecins Sans Frontières (2003) Emergency Nutrition Guidelines: Handbook for Field Managers and Clinicians. Geneva: Médecins Sans Frontières.

41. Filteau S (2009) The HIV-exposed, uninfected African child. Trop Med Int Health 14, 276-287.

42. Piwoz EG, Humphrey JH, Tavengwa NV et al. (2007) The impact of safer breastfeeding practices on postnatal HIV-1 transmission in Zimbabwe. Am J Public Health 97, 1249-1254.

43. Tabi M \& Vogel RL (2006) Nutritional counselling: an intervention for HIV-positive patients. J Adv Nurs 54, 676-682.

44. Fadnes LT, Engebretsen IM, Wamani H et al. (2009) Need to optimise infant feeding counselling: a cross-sectional survey among HIV-positive mothers in Eastern Uganda. BMC Pediatr 9,2

45. DePee S \& Semba RD (2010) Role of nutrition in HIV infection: review of evidence for more effective programming in resource-limited settings. Food Nutr Bull 31, Suppl. 4, S313-S344.

46. Burbano X, Miguez-Burbano MJ, McCollister K et al. (2002) Impact of a selenium chemoprevention clinical trial on hospital admissions of HIV-infected participants. HIV Clin Trials 3, 483-491.

47. Kaiser JD, Campa AM, Ondercin JP et al. (2006) Micronutrient supplementation increases CD4 count in HIVinfected individuals on highly active antiretroviral therapy: a prospective, double-blinded, placebo-controlled trial. J Acquir Immune Defic Syndr 42, 523-528.

48. Irlam JH, Visser MME, Rollins N et al. (2010) Micronutrient supplementation in children and adults with HIV infection. Cochrane Database Syst Rev issue 12, CD003650.
49. Drain PK, Kupka R, Mugusi F et al. (2007) Micronutrients in HIV-positive persons receiving highly active antiretroviral therapy. Am J Clin Nutr 85, 333-345.

50. Koethe JR, Chi BH, Megazzini KM et al. (2009) Macronutrient supplementation for malnourished HIV-infected adults: a review of the evidence in resource-adequate and resource-constrained settings. Clin Infect Dis 49, 787-798.

51. Rosen S, Fox MP \& Gill CJ (2007) Patient retention in antiretroviral therapy programs in sub-Saharan Africa: a systematic review. PloS Med 4, e298.

52. Brinkhof MW, Dabis F, Myer L et al. (2008) Early loss of HIV-infected patients on potent antiretroviral therapy programmes in lower-income countries. Bull World Health Organ 86, 559-567.

53. Byron E, Gillespie S \& Nangami M (2008) Integrating nutrition security with treatment of people living with HIV: lessons from Kenya. Food Nutr Bull 29, 87-97.

54. Cantrell RA, Sinkala M, Megazinni K et al. (2008) A pilot study of food supplementation to improve adherence to antiretroviral therapy among food-insecure adults in Lusaka, Zambia. J Acquir Immune Defic Syndr 49, 190-195.

55. Nash D, Korves C, Saito S et al. (2008) Characteristics of facilities and programs delivering HIV care and treatment services are associated with loss to follow-up rates in programs from 8 sub-Saharan African countries (abstract no. 838). Presented at 15 th Conference on Retroviruses and Opportunistic Infections (CROI 2008), Boston, MA, 3-6 February 2008.

56. Chilenje Infant Growth Nutrition and Infection Study Team (2010) Micronutrient fortification to improve growth and health of maternally HIV-unexposed and exposed Zambian infants: a randomised controlled trial. PloS One 5, e11165.

57. Mapunjo S \& Urassa DP (2007) Quality standards in provision of facility based HIV care and treatment: a case study from Dar es Salaam Region, Tanzania. East Afr J Public Health 4, 12-18.

58. Briend A, Prudhon C, Prinzo ZW et al. (2006) Putting the management of severe malnutrition back on the international health agenda. Food Nut Bull 27, Suppl. 3, S3-S6.

59. Bahwere P, Sadler K \& Collins S (2009) Acceptibility and effectiveness of chickpea sesame-based ready-to-use therapeutic food in malnourished HIV positive adults. Patient Prefer Adherence 3, 67-75.

60. Ndekha MJ, Manary MJ, Ashorn P et al. (2005) Home-based therapy with ready-to-use therapeutic food is of benefit to malnourished, HIV-infected Malawian children. Acta Paediatr 94, 222-225.

61. World Health Organization (2009) Towards Universal Access: Scaling up Priority HIV/AIDS Interventions in the Health Sector: Progress Report. Geneva: WHO; available at http://www.data.unaids.org/pub/Report/2009/20090930_ tuapr_2009_en.pdf

62. King G, Rosen O \& Tanner MA (2004) Ecological Inference: New Methodological Strategies. New York: Cambridge University Press.

63. World Health Organization (2004) National AIDS Programmes: A guide to Monitoring and Evaluating HIV/AIDS Care And Support. Geneva: WHO; available at http://www.data.unaids. org/publications/irc-pub06/jc1013-caresupport_en.pdf

64. United Nations General Assembly Special Session on HIV/AIDS (2009) Monitoring the Declaration of Commitment on HIV/AIDS: Guidelines on the Construction of Core Indicators. 2010 Reporting. Geneva: WHO; available at http://www.data.unaids.org/pub/manual/2009/jc1676_core_ indicators_2009_en.pdf 